\title{
Article
}

\section{Enhancing social networks: a qualitative study of health and social care practice in UK mental health services}

\author{
Webber, M, Reidy, H, Ansari, D, Stevens, M and Morris, David \\ Available at http://clok.uclan.ac.uk/11394/ \\ Webber, M, Reidy, H, Ansari, D, Stevens, M and Morris, David ORCID: 0000- \\ 0001-7372-8084 (2015) Enhancing social networks: a qualitative study of \\ health and social care practice in UK mental health services. Health and Social \\ Care in the Community, 23 (2). pp. 180-189.
}

It is advisable to refer to the publisher's version if you intend to cite from the work. http://dx.doi.org/10.1111/hsc.12135

For more information about UCLan's research in this area go to http://www.uclan.ac.uk/researchgroups/ and search for <name of research Group>.

For information about Research generally at UCLan please go to http://www.uclan.ac.uk/research/

All outputs in CLoK are protected by Intellectual Property Rights law, including Copyright law. Copyright, IPR and Moral Rights for the works on this site are retained by the individual authors and/or other copyright owners. Terms and conditions for use of this material are defined in the policies page.

\section{CLoK}

Central Lancashire online Knowledge www.clok.uclan.ac.uk

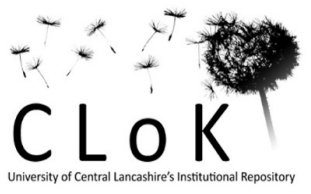




\title{
Enhancing social networks: a qualitative study of health and social care practice in UK mental health services
}

\author{
Martin Webber BA (Hons) MSc DipSW MSc PhD FRSA ${ }^{1}$, Hannah Reidy BA (Hons) ${ }^{2}$, David Ansari MSc ${ }^{3}$, \\ Martin Stevens $\mathrm{PhD}^{2}$ and David Morris PhD BA CQSW DASS FRSA ${ }^{4}$ \\ ${ }^{1}$ Department of Social Policy and Social Work, University of York, Heslington, York, UK, ${ }^{2}$ Social Care Workforce \\ Research Unit, King's College London, London, UK, ${ }^{3}$ Department of Comparative Human Development, University of \\ Chicago, Chicago, Illinois, USA and ${ }^{4}$ School of Social Work, University of Central Lancashire, UK
}

Accepted for publication 20 June 2014

\section{Correspondence \\ Martin Webber \\ Department of Social Policy \\ and Social Work \\ University of York \\ Heslington, York YO10 5DD, UK \\ E-mail: martin.webber@york.ac.uk}

\section{What is known about this topic}

- Social capital, defined as resources held within networks, is recognised as being important to mental health.

- People with mental health problems have access to less social capital than the general population.

- There are no practice models or frameworks to assist practitioners to help people develop their social networks and enhance their access to social capital.

\section{What this paper adds}

- Health and social care agencies can help people enhance their access to social capital via social networks.

- Workers can help service users enhance their social connections by supporting them to engage in new activities within their communities.

- A person-centred approach which builds on service users' strengths appears to be most effective.

\begin{abstract}
People with severe mental health problems such as psychosis have access to less social capital, defined as resources within social networks, than members of the general population. However, a lack of theoretically and empirically informed models hampers the development of social interventions which seek to enhance an individual's social networks. This paper reports the findings of a qualitative study, which used ethnographic field methods in six sites in England to investigate how workers helped people recovering from psychosis to enhance their social networks. This study drew upon practice wisdom and lived experience to provide data for intervention modelling. Data were collected from 73 practitioners and 51 people who used their services in two phases. Data were selected and coded using a grounded theory approach to depict the key themes that appeared to underpin the generation of social capital within networks. Findings are presented in four over-arching themes worker skills, attitudes and roles; connecting people processes; role of the agency; and barriers to network development. The sub-themes which were identified included worker attitudes; person-centred approach; equality of worker-individual relationship; goal setting; creating new networks and relationships; engagement through activities; practical support; existing relationships; the individual taking responsibility; identifying and overcoming barriers; and moving on. Themes were consistent with recovery models used within mental health services and will provide the basis for the development of an intervention model to enhance individuals' access to social capital within networks.
\end{abstract}

Keywords: mental health, recovery, social capital, social intervention, social networks, social work

\section{Introduction}

Social capital is increasingly being recognised as important for health and mental well-being (Kawachi et al. 2007). It is also increasingly being articulated as a useful concept for social work (Webber 2005, Hawkins \& Maurer 2012), particularly as it could assist in the development of new social interventions, which may support an individual's recovery from a mental health problem. Defined by Lin and others as the resources that are embedded within social networks (Lin 2001, Lin \& Erickson 2008), social capital can lead to greater occupational prestige, income and political influence when mobilised (Lin 2001). This 
conception is an extension of the social network theory and emphasises the importance of network members' resources, such as wealth, power and status, to an individual. It differs from communitarian notions of social capital (Putnam 1993), in that its benefits accrue to individuals rather than to groups.

Lin (2001) suggested that individuals can anticipate returns from their investment in social relationships through four mechanisms, which may improve their mental health. First, the provision of expert information from network members about the most effective interventions or health behaviours (Zambon et al. 2010, Song \& Chang 2012) or employment opportunities (Flap 1999), for example, can promote recovery. Second, the power and authority of network members may exert a similar influence on health that individually possessed power and social ordering has on exposure and vulnerability to health risks (Song 2007). Alternatively, the material resources of network members such as cheap loans to an individual with mental health problems, whose own resources are depleted through unemployment or long-term sick leave, could help alleviate debt or provide new opportunities (Lin 2001). Third, network members' resources may act as social credentials and, in this manner, could directly intervene in health and social care (Song 2011). Fourth, network members' resources can reinforce an individual's identification with a group and help maintain subjective social status (Song 2007), which may help promote mental health.

Social capital is unequally distributed within societies, by age, gender and health status (Kawachi et al. 1997). Furthermore, people experiencing long-term mental health problems or short-term psychological distress have access to less social capital than the general population (Webber \& Huxley 2007, Dutt \& Webber 2010, Song 2011, Webber et al. 2011). Inequalities in access to social capital arise through social network attrition associated with the pushing and pulling' away of friends and family members during the onset of severe mental health problems (Hawkins \& Abrams 2007). Impaired social functioning due to symptoms of mental health problems (Gotlib \& Lee 1989), social rejection (Perry 2012) and discrimination (Thornicroft 2006), and strategies people employ to cope with stigma (Link et al. 1989) have all been shown to reduce network size. Additionally, an inverse correlation has been found between access to social capital and experiences of discrimination (Webber et al. 2014).

Although some social care workers help people build relationships and strengthen their connections with their local community (Huxley et al. 2009), this is afforded a low priority by many (McConkey \&
Collins 2010). There is good evidence that positive and supportive social relationships are associated with well-being (Brugha et al. 2005, Aked et al. 2008, Bowling 2011, Webber et al. 2011) and that practitioners should aim to enhance individuals' networks to provide this (MacDonald et al. 2005, Yeung et al. 2013). However, there is limited evidence about social interventions, which assist people with mental health problems to enhance their social networks (Newlin et al. in press).

Informed by the Medical Research Council (2008) guidance on developing and evaluating complex interventions, this study is the first stage in the development of an intervention to enhance social networks (Webber 2014). This study aimed to understand how practitioners help people recovering from psychosis to develop their social networks. In particular, we aimed to investigate how workers created new opportunities for social engagement; discussed individuals' concerns about creating and maintaining social relationships; supported the development of social relationships with resourceful people (and their understanding of 'resourcefulness' in this context); and supported the process of investing in, and utilising, social capital held within networks.

\section{Method}

\section{Design and setting}

We conducted a qualitative study of practice in six health and social care agencies in England using combinative ethnographic methods (Baszanger \& Dodier 1997). This involved collecting data on a range of social network enhancement activities in six diverse contexts to allow us to generate general principles of practice through comparisons of individual experiences:

- Agency A was an inner-city third sector project, which connected people with mental health problems with others with shared interests;

- Agency B was an inner-city social enterprise, which helped young people with psychosis to develop new relationships through playing sport;

- Agency C was a National Health Service (NHS) early intervention in psychosis service in a mixed catchment area of countryside and large towns;

- Agency D was a large third sector housing support agency with many services across both inner and outer city locations;

- Agency E was an inner-city NHS social inclusion team supporting the recovery of people with psychosis;

- Agency F was an NHS early intervention in psychosis service covering a large rural area. 
Agencies were selected purposively to provide diverse practice contexts, which is an important consideration in social capital research (Dudwick et al. 2006). They all appeared to be engaged in social network enhancement activities on the basis of prior discussions with practitioners and managers. Agencies were selected from the NHS, voluntary and third sectors in rural and urban areas because it was anticipated that the context for practice played a significant role in shaping the relationships between practitioners and service users, and influencing the ability of workers to support individuals with their social networks.

\section{Sample}

Sample selection was guided by social capital theory (Lin 2001). We provided managers from each agency with a briefing paper containing information about the study, the definition of social capital used in the study and case studies which appeared to exemplify social network development. They initially identified a small number of workers who they considered to be adept in the practice domains we aimed to explore. As familiarisation with the agencies and workers grew, the researcher recruited subsequent workers to participate in the study. The inclusion criteria were any worker in the participating teams or agencies (including social workers, occupational therapists, community mental health nurses, social care workers and volunteers) who appeared skilled in connecting service users with other people. Managers did not place any restrictions on access to practitioners, which enabled us to purposively select workers in both data collection phases until data saturation was achieved in each of the practice areas. As researchers led the selection of participants, there was very little self-selection of practitioners to the study.

We recruited a sample of people recovering from an episode of psychosis who were in their first or second engagement with mental health services to participate in the study. The only selection criterion we used was for participants to be receiving a service from the agency. Participants were largely between 16 and 35 years of age, as this was a typical inclusion criterion for early intervention in psychosis services (Patton et al. 2007), but the sample was not restricted by age or diagnosis. In the social inclusion projects (agencies A and E), we also included people with other mental health problems, and those above the age of 35 , to obtain their experience of innovative practice that may not have been captured elsewhere in the study. Initially, staff members gave information about the study to service users who may have been interested in participating. However, as the researchers became more familiar with the services and their users, they were able to purposively select participants to obtain a diversity of experiences and perspectives on the research questions. Staff members allowed researchers full access to service users and only played a limited gatekeeping role in the NHS teams where they advised on who may lack capacity to participate because of experiencing an acute episode of psychosis. Although it is possible that staff may have influenced sample selection, researchers were able to mitigate any bias this may have caused by recruiting directly from among service users.

Sample sizes were guided by theoretical saturation (Glaser \& Strauss 1967) across the practice domains of the study. Analysis was iterative and ongoing throughout the study, and we continued to recruit both workers and service users until themes were saturated and no new themes emerged in subsequent data collection. Recruitment was spread across the participating agencies in both data collection phases so that the samples were not disproportionately drawn from one agency. Although no target sample sizes were set, we ensured that participants broadly reflected the socio-demographic characteristics of workers and service users in the agencies they were recruited from.

\section{Data collection}

The field work was conducted from November 2010 to March 2012 in two phases using a sequential iteration method by which the researcher spent time within different teams, sites and settings in distinct phases of the data collection process. Ethnographic field methods of semi-structured interviews, unstructured interviews, non-participant observation, participant observation and informal discussions were used, with participants providing informed consent at each stage. Information sheets about the study were provided to practitioners and service users, with easyread versions provided to participants with limited ability to understand written English. Potential participants were provided with an opportunity to ask researchers questions about the study before giving their consent to participate. Participants' consent was sought for participation in each discrete element of the study. For example, if participants provided data in an interview, continued consent was not assumed and was separately obtained for involvement in subsequent observations. When the researcher participated in or observed groups or meetings, all service users and staff received prior notification that the researcher would like to use the opportunity for data 
collection and were asked for their informed consent for the researcher to participate. On occasions when staff or service users were not comfortable with a researcher observing a group or meeting, the observation did not go ahead to minimise disruption.

The first phase of the fieldwork began with the researcher interviewing workers using a semi-structured schedule to explore how they supported people to develop their social networks. Workers were asked to describe how they developed working relationships with service users, what they understood by resourcefulness and what they did to connect service users with resourceful people. Additionally, they were asked to provide examples from their recent practice of when they had successfully supported an individual to develop new, or maintain existing, social connections, and to discuss the barriers both they and service users faced during this process. Interviews typically lasted between 30 and 90 minutes.

This was followed by observations of their practice to explore the extent to which their practice related to their prior descriptions. This involved becoming part of groups and undertaking activities (participant observation), and shadowing workers observing their interactions with individuals (nonparticipant observation). Researchers observed the 'soft skills' involved in nurturing social connections; the activities which workers used as the context for connecting people; and the support provided by workers to maintain existing relationships. Participant observations typically occurred within an agency or another community location where groups were facilitated. Non-participant observations typically occurred in service users' homes, within an agency meeting room or in a community location, according to where the worker and service user met. Observations ranged in duration from brief encounters of less than 30 minutes to spending a whole day with a worker or a group. As the focus of observations was on how workers developed inter-personal relationships between individuals or within groups, the intensity of the observation varied according to its context.

The researcher developed strong relationships with the agencies and workers to permit access to multiple opportunities for observations, which allowed us to experience practice in as many situations as possible. This included regular groups based on arts and crafts, peer support or sport, for example, and one-off events such as concerts or exhibitions in which service users participated alongside other members of the local community. These strong relationships also allowed the triangulation of data from multiple sources, enhancing the reliability of our findings.
The observations involved service users who met the inclusion criteria for the study, with their informed consent. Following the observation, each service user was invited to participate in a brief semistructured interview (without their worker present) to explore their experiences of this practice. Service users were asked to discuss their perceptions of the effectiveness of their worker in supporting them with their social connections and the barriers they faced in connecting with other people. Interviews typically lasted between 30 and 60 minutes. The sequence of worker interview $\rightarrow$ observation $\rightarrow$ service user interview was not strictly followed to permit the pragmatic inclusion of data collection opportunities as they arose.

During each 6-month phase of data collection, researchers spent time within agencies to understand the context of workers' practice and the structural constraints and enablers of social connections. This varied from a day a week to a whole week at a time, depending on opportunities for data collection. Field notes were made throughout this process, and informal conversations were documented to record interactions and ways of working that may be important for social network enhancement interventions. This process enabled researchers to develop a thick description' of workers' practice in their respective contexts.

A second 6-month data collection phase was conducted following analysis of phase 1 data to ensure that data saturation was achieved. Phase 2 data collection focused on confirming emergent themes from phase 1; answering research questions which phase 1 data collection did not fully address; and obtaining a more in-depth understanding of the context of each agency. Similar data collection methods were used, but theories about intervention development from phase 1 were taken into the phase 2 field work to avoid repetition and allowed us to work towards data saturation. Additionally, individuals and workers with different points of view were sought to ensure that diverse opinions were represented.

While phase 2 predominantly included new workers and service users, we interviewed eight workers and two service users who participated in phase 1 approximately 6 months following their first interview. This semi-structured interview focused on how the worker's practice had influenced the service user's ability to make and maintain relationships, and enhance their access to social capital.

\section{Data analysis}

Interviews were audio-recorded and transcribed in full for analysis. Contemporaneous field notes were 
made by the researcher throughout the data collection phases, particularly the participant and nonparticipant observations, to capture practice contexts. Data were analysed as an iterative process throughout data collection using the constant comparative method in grounded theory (Glaser \& Strauss 1967). Data were analysed at the individual level of service users and workers as the study aimed to explore individual practice. We explored the perspectives of worker-service user dyads where possible, although this did not extend to a full social network approach to analysis.

NVivo v.10 was used to assist tasks of coding, retrieving and comparing data. Analysis involved a detailed reading and re-reading of the text (both transcripts and field notes) to identify initial themes in NVivo, which were refined through comparisons of text subsumed under each thematic category. This initial process was undertaken by two researchers working independently to enhance reliability and minimise the potential for bias. An initial coding framework was developed in NVivo and used as a tool to guide questions within subsequent fieldwork. It was used as a lens through which to observe the agencies and individuals that they worked with. Coding of subsequent field work within NVivo proceeded along two different dimensions.

First, topics were assigned to the following themes: 'agency', 'worker', 'individual' or 'practice'. 'Practice' referred to actions taken by workers which appeared to help an individual enhance their social networks. Practice is conceptualised here as the exercise of a profession or what practitioners do in the course of performing their duties. In contrast, 'worker' encompassed the personal qualities of a worker, or examples of practice that were specific to one worker in particular. 'Agency' referred to the organisation as a whole, as well as other organisations that participants had experienced in the past. The 'individual' domain included text about the users of the service. Text referring to more than one theme was coded multiple times. As the focus of this study was on professional practice, we did not separately code the social processes of forming and maintaining social relationships which, although important, required a separate analysis.

Second, a grounded approach was used to code data by subject in more detail (Glaser \& Strauss 1967). Data were analysed sequentially from each agency involved in the study, first from the perspective of workers (managers, frontline staff and volunteers) and then from each agency's service users. At this point, the coding framework in NVivo was refined to combine similar nodes, reducing the node count from over 100 codes to 13 overarching themes.

Triangulation was achieved in the analysis through comparison of worker and service user perspectives within each agency, and between the two phases of data collection. Data from phase 2 interviews with the 10 people who had been interviewed in phase 1 were integrated into the analysis to explore the outcomes of workers' practice and triangulate findings between data collection phases.

Finally, six transcripts were picked at random and coded according to this new coding framework in NVivo, to ensure that no themes had been missed. No new themes emerged from the data, so it was assumed that saturation had been reached. The analysis was largely conducted by the field worker, although the principal investigator was involved throughout in discussing coding structures and thematic categories to further enhance reliability.

Ethical approval for the study was provided by the NW London NHS Research Ethics Committee 2 (ref. 10/H0720/48).

\section{Results}

In total, 73 workers and volunteers participated in the study (Table 1). The gender, ethnicity and occupational profiles of the sample were typical of the mental health workforce in England (Health and Social Care Information Centre 2013, 2014), although social care staff were overrepresented because of the social interventions being studied. Also, there were a higher proportion of people aged under 40 in the sample, possibly because those working in early intervention in psychosis services are typically younger (Lester et al. 2007).

A total of 51 service users participated in the study (Table 1). The predominance of men, younger age groups and an overrepresentation of black ethnic groups in our sample was typical of the epidemiology of psychosis in England (Sadler \& Bebbington 2009) and the target population for this study.

The presentation of findings starts with the skills and attitudes of the worker, which appear necessary for social network enhancement activities, and is followed by an examination of the processes associated with connecting people. The role of the agency is considered separately as it provides the context for the practice explored in this paper. Finally, the barriers to social network development are explored. Findings are presented as the shared perspectives and experiences of service users and workers, although different opinions are highlighted where relevant. 
Table 1 Socio-demographic profile of participants

\begin{tabular}{|c|c|c|}
\hline & $\begin{array}{l}\text { Workers } \\
n=73(\%)\end{array}$ & $\begin{array}{l}\text { Service users } \\
n=51(\%)\end{array}$ \\
\hline \multicolumn{3}{|l|}{ Gender } \\
\hline Male & $30(41.1)$ & $32(62.7)$ \\
\hline Female & $43(58.9)$ & 19 (37.3) \\
\hline \multicolumn{3}{|l|}{ Age (in years) } \\
\hline$<20$ & $1(1.4)$ & $5(9.8)$ \\
\hline $20-29$ & $12(16.4)$ & 27 (52.9) \\
\hline $30-39$ & $13(17.8)$ & $6(11.8)$ \\
\hline $40-49$ & $14(19.2)$ & $6(11.8)$ \\
\hline $50-59$ & $16(21.9)$ & $3(5.9)$ \\
\hline$>60$ & $1(1.4)$ & 0 \\
\hline Not given & $16(21.9)$ & $4(7.8)$ \\
\hline \multicolumn{3}{|l|}{ Ethnic group } \\
\hline White British & $43(58.9)$ & $32(62.7)$ \\
\hline Other white ethnicity & $5(6.8)$ & $1(2.0)$ \\
\hline Asian/Asian British & $1(1.4)$ & $3(5.9)$ \\
\hline Black/Black British & $7(9.6)$ & $10(19.6)$ \\
\hline Other ethnicity & $3(4.1)$ & $3(5.9)$ \\
\hline Not given & $14(19.2)$ & $2(3.9)$ \\
\hline \multicolumn{3}{|l|}{ Worker role } \\
\hline Manager/team leader & $13(17.8)$ & \\
\hline Support worker & $13(17.8)$ & \\
\hline Social worker & $7(9.6)$ & \\
\hline Social work student & $2(2.7)$ & \\
\hline $\begin{array}{l}\text { Community mental } \\
\text { health nurse }\end{array}$ & $5(6.8)$ & \\
\hline Occupational therapist & $2(2.7)$ & \\
\hline Clinical psychologist & $1(1.4)$ & \\
\hline General practitioner & $1(1.4)$ & \\
\hline $\begin{array}{l}\text { Other workers } \\
\text { (e.g. health and } \\
\text { well-being worker) }\end{array}$ & $17(23.3)$ & \\
\hline Volunteer & $12(16.4)$ & \\
\hline
\end{tabular}

\section{Worker skills, attitudes and roles}

The attitude of the worker towards social network enhancement appeared central to the likely success of interventions. As in models of recovery wherein practitioners can play a key role in fostering hope (Leamy et al. 2011), workers with a 'can-do attitude' appear to be more effective. This attribute encompassed the capacity to do things quickly, flexibly, confidently, enthusiastically and to enjoy the job (e.g. Figure 1).

Relationship building skills appeared to be equally important. These included having a sense of humour and being friendly. Body language and communication skills were also key, as well as patience and time

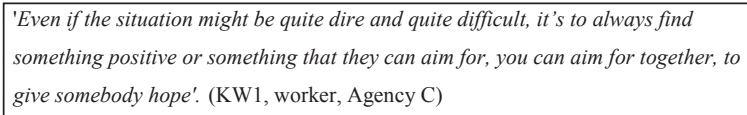

Figure 1 Worker attitudes. to spend being supportive, reflective, and having selfawareness and insight. A person-centred approach (Rogers 1959) and the centrality of the service user appeared to be important as intervention success appeared to depend on listening and responding to what an individual was interested in and wanted to achieve, rather than being designed by the service. However, positive attitudes occasionally needed to be more actively conveyed to an individual to promote that person's confidence, responsibility, hope and empowerment. An absence of these 'soft skills' in our data was notable, suggesting a potential training need for workers.

Although context-dependent, clarity about professional boundaries and roles appeared important, allowing workers to act within them accordingly and not feel too constrained by them. However, a clear difference emerged between the NHS and third sector agencies on this point, with a greater blurring of roles in the latter (Figure 2).

More equal relationships between a worker and a service user appeared to be important in supporting someone to develop their network. Respect, a shared sense of identity, honesty and trust, and empathy from shared lived experience appeared important elements of equal relationships. In NHS mental health services, however, where professionals frequently held considerable power, including the means to compulsorily detain individuals in hospital, this was often problematic.

\section{Processes involved in connecting people}

The exposure of a service user to new ideas appeared to be a key element in the process of identifying opportunities for connecting people and developing social networks. To do this effectively, a worker needed to be continuously thinking about potential opportunities as a component of everyday practice, and actively identifying opportunities when they arose. For a service user to be more likely to engage with these new ideas, it

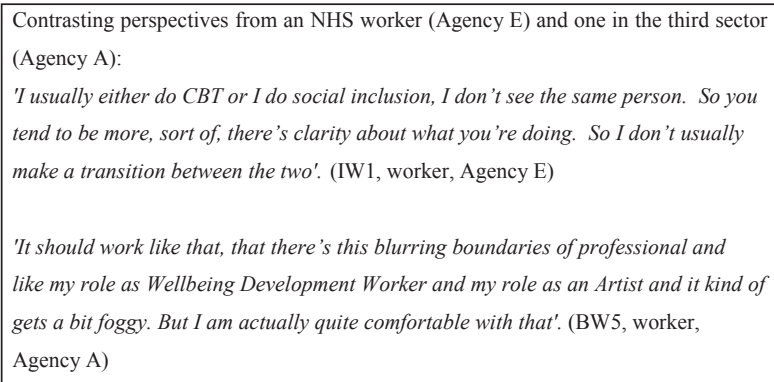

Figure 2 Worker roles. 
appeared to help if a worker shared their personal experiences and resources (Figure 3).

Once a relationship had been formed and new ideas discussed, the worker and service user set goals together. Successful goals appeared to be tangible and realistic, articulated in clear steps which did not overwhelm the individual. The creation of new networks and relationships in the course of attaining these goals provided the context for the creation of social capital. Workers assisted by introducing service users to new people with similar interests either within the agency or to resourceful people outside the agency. Both service users and workers identified that workers needed to develop new contacts to help facilitate this process.

Workers identified new contacts by word of mouth, as well as networking both within and outside their organisation. Engagement with local communities (geographical or interest) appeared to be at the heart of this process. This active process corresponded with the less tangible, attitudinal element of finding out about new ideas during their daily work from colleagues and their networks.

When fostering and nurturing enthusiasm for the process appeared problematic, engaging in activities appeared to be an effective approach to connecting people (Figure 4). The activity was either provided by the agency or was one the worker and the service user decided upon together. However, the motivation to attend an activity, group or scheme was important, as was the self-awareness and existing knowledge of a service user, which appeared to increase self-confidence.

Building a service user's skills and providing them with the opportunity to use or share them appeared effective tools in connecting people. Additionally, practical support from the worker - such as help with a $\mathrm{CV}$ or job applications, or with managing personal finances - was perceived by service users as being important in helping them to achieve their goals.

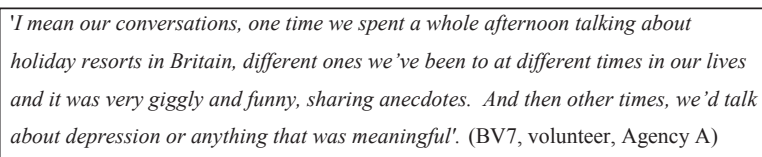

Figure 3 Sharing experiences.

2 hours'. (SS7, service user, Agency B)

Figure 4 Activities.
Attending activities or interviews together and introducing a service user to a new environment were also seen as potentially useful as it gave them confidence to try new things. By gaining new skills and confidence facilitated by workers and the agency, and taking responsibility for working towards their goals, service users who tried new activities formed new social ties in their local community or community of interest. Graded exposure techniques (De Silva \& Rachman 1981) were used quite frequently. Service users who were provided with flexible ongoing support reported feeling more secure than if they were left to attend new activities alone, particularly those who lacked in confidence or were fearful of discrimination because of their mental health problem.

\section{Role of the agency}

The extent to which the agency engaged with its local community appeared to influence its ability to develop service users' personal networks. Health and social care services facilitated bonding social capital by linking homogeneous individuals in shared activities, particularly when they provided a nurturing, friendly environment, which did not feel too 'clinical'. Arguably, more importantly, however, they supported the formation of bridging social capital by introducing individuals to training, employment or other opportunities, which connected them to heterogeneous others. Additionally, strong connections within an agency appeared to be associated with the sharing of information and fostering of external connections (Figure 5). Third sector agencies embedded within local communities which used non-stigmatised locations appeared more successful in facilitating social connections, although this needs to be empirically verified.

Many participants discussed, or were observed developing, relationships with other users of the service they were receiving. Friendships and relationships formed naturally and we observed only a few instances when workers intervened to support the development of an individual's social skills to facilitate this process. Teamwork, social networking and undertaking shared activities based on shared experiences aided the formation of relationships. Some individuals found that these 'safe' interactions within the agency helped their confidence in forming other relationships externally. However, several service users described the agency as a place which they went to for its facilities and to see their worker, rather than as a place to make friends. Although we observed the development of social connections within agencies, this paper did not specifically explore the role of peer 


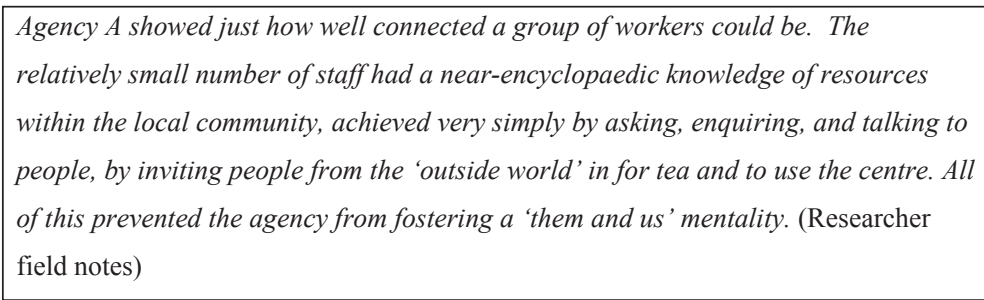

Figure 5 Community connections.

support in the development of social networks, which merits further research (Lloyd-Evans et al. 2014).

\section{Barriers to network development}

Barriers to developing social networks appeared prominent throughout the fieldwork and could be categorised as attitudinal or contextual. Stigma of mental health problems and negative attitudes of others were prevalent barriers. Contextual barriers appeared to be shared by both workers and service users, mostly characterised by a lack of resources such as money, transport, knowledge, time or support. Barriers were not perceived as insurmountable by the more positive workers, and service users who acknowledged them explored ways around them and sought to overcome them. Although barriers prevented individuals moving continuously forward in a linear journey, many achieved their goals by other means or took longer than originally planned.

\section{Discussion}

This is the first study to explore the processes involved in health and social care agencies which are supporting people recovering from an episode of acute mental illness to develop their social networks, although its findings mirror ethnographic studies of similar contexts (e.g. Simpson-Young 2008). Our findings suggest that shifting the focus of clinicians away from deficits in the social functioning of people with psychosis (e.g. Brugha et al. 1993) to identifying assets and shared interests among them (Rapp \& Goscha 2011) encourages social engagement. This study supports Perry's (2012) findings that changes in social environments impact the social networks of people with severe mental health problems. It appears that providing meaningful opportunities for isolated people to meet others who share their interests can support the development of their social networks and improve their access to social capital.

This study is limited to the experience of practice within six agencies. It is possible that other agencies were working in other potentially more effective ways, but we were unable to capture this within this study. It is also possible that our observations and interview questions were unduly shaped by our preconceptions of what social network enhancement practice might look like. The initial nomination of workers by managers may have skewed the sample, but the inclusion of a large number of people in this qualitative study helped to counter sampling bias. However, the possibility remains that some perspectives were not adequately captured. For example, a larger number of workers participated than service users, which may have biased our findings towards the perspectives of the former.

People who identified themselves as carers or family members of the service users were largely absent from the sample. This was not intentional, but was possibly caused by our recruitment strategy, which focused on agencies and not families. Also, many of the study participants did not have carers or family members involved in their care or support, although the importance of family members was emphasised by those who did.

Our approach to data collection provided us with simultaneous insights into multiple practice contexts, which enabled us to test emerging theories in different sites. However, the study's focus on a small number of agencies and its iterative nature possibly made it difficult to directly compare practice between the participating agencies. A survey approach would have obtained data from a larger number of sites facilitating comparison between them, although it would have failed to capture rich contextual data. A further limitation of our methodology was a bias towards activities which may help generate social capital rather than those which may assist in its mobilisation. It is possible that this was a result of a focus on the development of social connections rather than utilising these social connections, as workers appear more familiar with the former than the latter. Additionally, as the focus of this study was on professional practice, we did not separately analyse the social processes of forming and maintaining social relationships which, although important, require separate consideration. 
This study found that agencies with stronger and more numerous connections with other community projects and networks appeared better able to connect service users with local opportunities. However, inter-agency working was not a significant focus of this study and further research is required to investigate its effectiveness in supporting the development of service users' networks.

\section{Conclusions}

While data in this study cannot be generalised to the whole population of people recovering from an episode of psychosis, our sample of workers and service users recruited from multiple contexts has helped us to identify practice components which appear effective. The modelling of these components will assist us to develop an intervention framework, which can be used to support workers in improving outcomes for service users. Intervention modelling will also permit replication of good practice and provide the basis for subsequent evaluation to help develop an evidence base for this neglected aspect of health and social care practice (Webber 2014).

\section{Acknowledgements}

This paper presents independent research funded by the NIHR School for Social Care Research. The views expressed in this paper are those of the authors and not necessarily those of the NIHR School for Social Care Research or the Department of Health, NIHR or NHS. The authors gratefully acknowledge the time given by the participants in this study and thank their agencies for providing access to their expertise.

\section{References}

Aked J., Marks N., Cordon C. \& Thompson S. (2008) Five Ways to Wellbeing. A Report Presented to the Foresight Project on Communicating the Evidence Base for Improving People's Well-Being. New Economics Foundation, London.

Baszanger I. \& Dodier N. (1997) Ethnography: relating the part to the whole. In: D. Silverman (Ed) Qualitative Research. Theory, Method and Practice, pp. 9-34. Sage, London.

Bowling A. (2011) Do older and younger people differ in their reported well-being? A national survey of adults in Britain. Family Practice 28, 145-155.

Brugha T.S., Wing J.K., Brewin C.R., MacCarthy B. \& Lesage A. (1993) The relationship of social network deficits with deficits in social functioning in long-term psychiatric disorders. Social Psychiatry and Psychiatric Epidemiology 28, 218-224.

Brugha T.S., Weich S., Singleton N. et al. (2005) Primary group size, social support, gender and future mental health status in a prospective study of people living in private households throughout Great Britain. Psychological Medicine 35, 705-714.

De Silva P. \& Rachman S. (1981) Is exposure a necessary condition for fear-reduction? Behaviour Research and Therapy 19, 227-232.

Dudwick N., Kuehnast K., Jones V.N. \& Woolcock M. (2006) Analyzing Social Capital in Context: A Guide to Using Qualitative Methods and Data. The World Bank, Washington, DC.

Dutt K. \& Webber M. (2010) Access to social capital and social support among South East Asian women with severe mental health problems: a cross-sectional survey. International Journal of Social Psychiatry 56, 593-605.

Flap H. (1999) Creation and returns of social capital. A new research program. La Revue Tocqueville XX, 5-26.

Glaser B.G. \& Strauss A.L. (1967) The Discovery of Grounded Theory: Strategies for Qualitative Research. Aldine, New York.

Gotlib I.H. \& Lee C.M. (1989) The social functioning of depressed patients: a longitudinal assessment. Journal of Social and Clinical Psychology 8, 223-237.

Hawkins R. \& Abrams C. (2007) Disappearing acts: the social networks of formerly homeless individuals with co-occurring disorders. Social Science and Medicine 65, 2031-2042.

Hawkins R.L. \& Maurer K. (2012) Unravelling social capital: disentangling a concept for social work. British Journal of Social Work 42, 353-370.

Health and Social Care Information Centre (2013) NHS Hospital and Community Health Service (HCHS) Workforce Statistics in England, Non-Medical Staff - 2002-2012, as at 30 September. Health and Social Care Information Centre, London.

Health and Social Care Information Centre (2014) Personal Social Services: Staff of Social Services Departments, England, as at September 2013. Health and Social Care Information Centre, London.

Huxley P., Evans S., Beresford P., Davidson B. \& King S. (2009) The principles and provisions of relationships: findings from an evaluation of Support, Time and Recovery Workers in mental health services in England. Journal of Social Work 9, 99-117.

Kawachi I., Kennedy B.P., Lochner K. \& Prothrow-Stith D. (1997) Social capital, income inequality, and mortality. American Journal of Public Health 87, 1491-1498.

Kawachi I., Subramanian S.V. \& Kim D. (Eds) (2007) Social Capital and Health. Springer-Verlag, New York.

Leamy M., Bird V., Le Boutillier C., Williams J. \& Slade M. (2011) Conceptual framework for personal recovery in mental health: systematic review and narrative synthesis. The British Journal of Psychiatry 199, 445-452.

Lester H.E., Tait L.A., Shah S., Birchwood M.J. \& Rogers H.J. (2007) Early Intervention Services: The Role of Psychiatrists and Partnership Working with the Voluntary and Community Sector. National Co-ordinating Centre for NHS Service Delivery and Organisation R\&D, London.

Lin N. (2001) Social Capital. A Theory of Social Structure and Action. Cambridge University Press, Cambridge.

Lin N. \& Erickson B. (Eds) (2008) Social Capital. An International Research Program. Oxford University Press, Oxford.

Link B.G., Cullen F.T., Struening E., Shrout P.E. \& Dohrenwend B.P. (1989) A modified labeling theory approach to mental disorders: an empirical assessment. American Sociological Review 54, 400-423.

Lloyd-Evans B., Mayo-Wilson E., Harrison B. et al. (2014) A systematic review and meta-analysis of randomised con- 
trolled trials of peer support for people with severe mental illness. BMC Psychiatry 14, 39.

MacDonald E., Sauer K., Howie L. \& Albiston D. (2005) What happens to social relationships in early psychosis? A phenomenological study of young people's experiences. Journal of Mental Health 14, 129-143.

McConkey R. \& Collins S. (2010) The role of support staff in promoting the social inclusion of persons with an intellectual disability. Journal of Intellectual Disability Research 54, 691-700.

Medical Research Council (2008) Developing and Evaluating Complex Interventions: New Guidance. Medical Research Council, London.

Newlin M., Morris D., Howarth S. \& Webber M. (in press) Social participation interventions for adults with mental health problems: a review and narrative synthesis. Social Work Research.

Patton G.C., Hetrick S.E. \& McGorry P. (2007) Service responses for youth onset mental disorders. Current Opinion in Psychiatry 20, 319-324.

Perry B.L. (2012) Coming untied? Narrative accounts of social network dynamics from first-time mental health clients. Sociology of Health and Illness 34, 1125-1139.

Putnam R. (1993) Making Democracy Work: Civic Traditions in Modern Italy. Princeton University Press, Princeton, NJ.

Rapp C. \& Goscha R. (2011) The Strengths Model. A Recovery-Oriented Approach to Mental Health Services. Oxford University Press, Oxford.

Rogers C. (1959) A theory of therapy, personality and interpersonal relationships as developed in the client-centered framework. In: S. Koch (Ed) Psychology: A Study of a Science. Vol. 3: Formulations of the Person and the Social Context, pp. 184-256. McGraw Hill, New York.

Sadler K. \& Bebbington P. (2009) Psychosis. In: S. McManus, H. Meltzer, T. Brugha, P. Bebbington \& R. Jenkins (Eds) Adult Psychiatric Morbidity in England, 2007. Results of a Household Survey, pp. 89-104. The Health and Social Care Information Centre, London.

Simpson-Young V. (2008) Meat Trays, Marginalisation and the Mechanisms of Social Capital Creation: An Ethnographic
Study of a Licensed Social Club and Its Older Users. Faculty of Health Sciences, University of Sydney, Sydney.

Song L. (2007) Your Body Knows Who You Know: Social Capital and Depressive Symptoms in the United States. Annual Meeting of American Sociological Association, New York.

Song L. (2011) Social capital and psychological distress. Journal of Health and Social Behavior 52, 478-492.

Song L. \& Chang T.-Y. (2012) Do resources of network members help in help seeking? Social capital and health information search. Social Networks 34, 658-669.

Thornicroft G. (2006) Shunned: Discrimination against People with Mental Illness. Oxford University Press, Oxford.

Webber M. (2005) Social capital and mental health. In: J. Tew (Ed) Social Perspectives in Mental Health: Developing Social Models to Understand and Work with Mental Distress, pp. 90-111. Jessica Kingsley Publishers, London.

Webber M. (2014) From ethnography to randomized controlled trial: an innovative approach to developing complex social interventions. Journal of Evidence-Based Social Work 11, 173-182.

Webber M.P. \& Huxley P.J. (2007) Measuring access to social capital: the validity and reliability of the Resource Generator-UK and its association with common mental disorder. Social Science and Medicine 65, 481-492.

Webber M., Huxley P. \& Harris T. (2011) Social capital and the course of depression: six-month prospective cohort study. Journal of Affective Disorders 129, 149-157.

Webber M., Corker E., Hamilton S. et al. (2014) Discrimination against people with severe mental illness and their access to social capital: findings from the Viewpoint survey. Epidemiology and Psychiatric Sciences 23, 155-165.

Yeung E.Y.-W., Irvine F., Ng S.-M. \& Tsang S.K.M. (2013) Role of social networks in the help-seeking experiences among Chinese suffering from severe mental illness in England: a qualitative study. British Journal of Social Work 43, 486-503.

Zambon A., Morgan A., Vereecken C. et al. (2010) The contribution of club participation to adolescent health: evidence from six countries. Journal of Epidemiology and Community Health 64, 89-95. 